\title{
Casa de las Américas, un indicio en el tiempo
}

\author{
Alejandra González Bazúa*
}

Recibido el 23 de junio de 2019; aceptado el 2 de octubre de 2019

\section{RESUMEN}

Este artículo es un acercamiento a la revista Casa de las Américas durante los años ochenta, período poco estudiado en esta publicación comparado con los vastos análisis de las dos décadas precedentes. En él se analizan tres números de la publicación. Su propuesta metodológica concibe a cada número de la revista como un "indicio", una serie de pistas cuya interpretación puede explicar relaciones de poder y dominación o de encuentro en el disenso. Dicha forma de acercamiento documental evoca la propuesta del "paradigma indiciario" de Carlo Ginzburg. Utilizar este acercamiento en el análisis permite visibilizar rasgos documentales casi imperceptibles, lo cual resulta fundamental en fuentes tan densas y complejas como las revistas culturales.

Casa de las Américas es una de las revistas más importantes del continente; estudiar los discursos y la materialidad de sus números en los ochenta da claves para comprender ciertos virajes en las relaciones entre política y cultura en una época de inflexión histórica. Como se verá en el artículo, en esta icónica revista cubana se reflejaron contradicciones y matices en torno al ideal y práctica de la Revolución cubana, en ella coincidieron pensamientos no unívocos.

Palabras clave: revistas culturales, Casa de las Américas, paradigma indiciario, Revolución cubana, América Latina.

* Universidad Nacional Autónoma de México, México. Correo electrónico: alebazua@gmail.com 


\title{
Casa de las Américas, a clue in the time
}

\begin{abstract}
This article is an approach to the Casa de las Américas magazine during the 1980 's, a period seldom studied in comparison to the numerous analysis realized on the previous two decades. The article focuses on three issues Its methodological proposal conceives each issue of the magazine as a "sign", a series of clues whose interpretation can explain the power and domination relationships or the convergence in the dissent. This form of documentary approach evokes the proposal of the "index paradigm" made by Carlo Ginzburg. Using this approach in the analysis helps to make visible almost imperceptible documentary features, an aspect which is essential in sources as dense and complex as cultural journals.

Casa de las Américas is one of the most important magazines in the continent. To study the discourses and the materiality of their issues in the 1980's gives clues to understand certain changes in the relations between politics and culture in a time of historical inflection. As we will see in this article, in the pages of this iconic Cuban magazine several contradictions and nuances were mirrored around the ideals of the Cuban Revolution and their practice. They showed the coexistence of non-univocal ways of thinking.
\end{abstract}

Key words: Cultural magazines, Casa de las Américas, index paradigm, Cuban Revolution, Latin America.

\section{INTRODUCCIÓN}

S esenta años han pasado desde que el fotógrafo cubano Alberto Korda accionó el obturador de su cámara después de encuadrar y enfocar a un campesino, cigarro en mano, subido en una farola en la Plaza de la Revolución en La Habana. La foto, conocida como El Quijote de la farola es una de las imágenes icónicas de la historia contemporánea de América Latina. Korda capturó con aquella imagen uno de los momentos del aniversario del asalto al cuartel Moncada. Era julio de 1959, seis meses habían pasado desde el inicio calendárico de la Revolución cubana.

Existen documentos fotográficos en los que se mira a los campesinos retratados por Korda comiendo en el vestíbulo de Casa de las Américas, ${ }^{1}$ 
institución cultural cubana fundada al calor del triunfo revolucionario. Desde sus inicios, este proyecto cultural y político tuvo como sede un icónico edificio al lado del malecón habanero, en el cual continúa sus actividades. A partir de su creación en abril de 1959, esta institución fue dirigida por Haydeé Santamaría, quien en 1953 participó en el Asalto al Cuartel Moncada. Santamaría fungió como su directora hasta 1980, año de su fallecimiento; posteriormente, por un breve período de seis años, la dirigió Mariano Rodríguez; a partir de 1986 y hasta julio de 2019, Casa de las Américas fue dirigida por Roberto Fernández Retamar, quien en el cincuenta aniversario de la institución reconoció la herencia de Haydée Santamaría en este proyecto cultural cubano. $^{2}$

Justo un año después de que aquella escena fotográfica, en el verano de 1960 se publicó el primer número de Casa de las Américas, revista que se planteó ser la materialización en tinta y papel de la institución que la cobija desde entonces. Desde sus primeros números buscó ser un lugar de encuentro y diálogo entre el proyecto emanado de la Revolución cubana y la intelectualidad mundial, principalmente latinoamericana.

Esta revista es una de las más longevas de nuestro continente, su acervo, cercano a los trescientos números, resguarda parte de la memoria cultural y política latinoamericana de la segunda mitad del siglo xx y lo que va del XXI.

Se llamó “Casa de las Américas” y no "Casa para las Américas”. Importa resaltar la preposición "de” porque en la multiplicidad de textos de esta revista, en los que se utiliza la idea de Casa como metáfora identitaria, se concibe no como un lugar al que se llega, sino como espacio al que se pertenece. La idea de esta Casa es más cercana a la palabra hogar que a la de simple espacio edificado; era un lugar para habitar, un espacio significado por generaciones de pensamiento que trascendían el momento de su fundación. Las acciones de sus habitantes eran claras: se articulaban los revolucionarios, se reivindicaban luchas, se denunciaba el imperialismo, se rememoraba la rebeldía, se imaginaba la emancipación continental. Era un hogar, una casa que se distinguía y diferenciaba tajantemente de otros espacios. Era una Casa punto de encuentro, punto de partida, Casa paisaje, Casa

Fundación de Sevilla, http://www.casa.co.cu/pdfmemo/1959-1969.pdf, consultado el 25 de febrero de 2019.

2 Roberto Fernández Retamar, "El más grande honor de mi vida", www.lacult.unesco.org/docc/Dossier_50_Aniv_CASA_09.doc, consultado el 25 de febrero de 2019. 
con jardín martiano, dijo Mario Benedetti en el aniversario número XX de la publicación. ${ }^{3}$

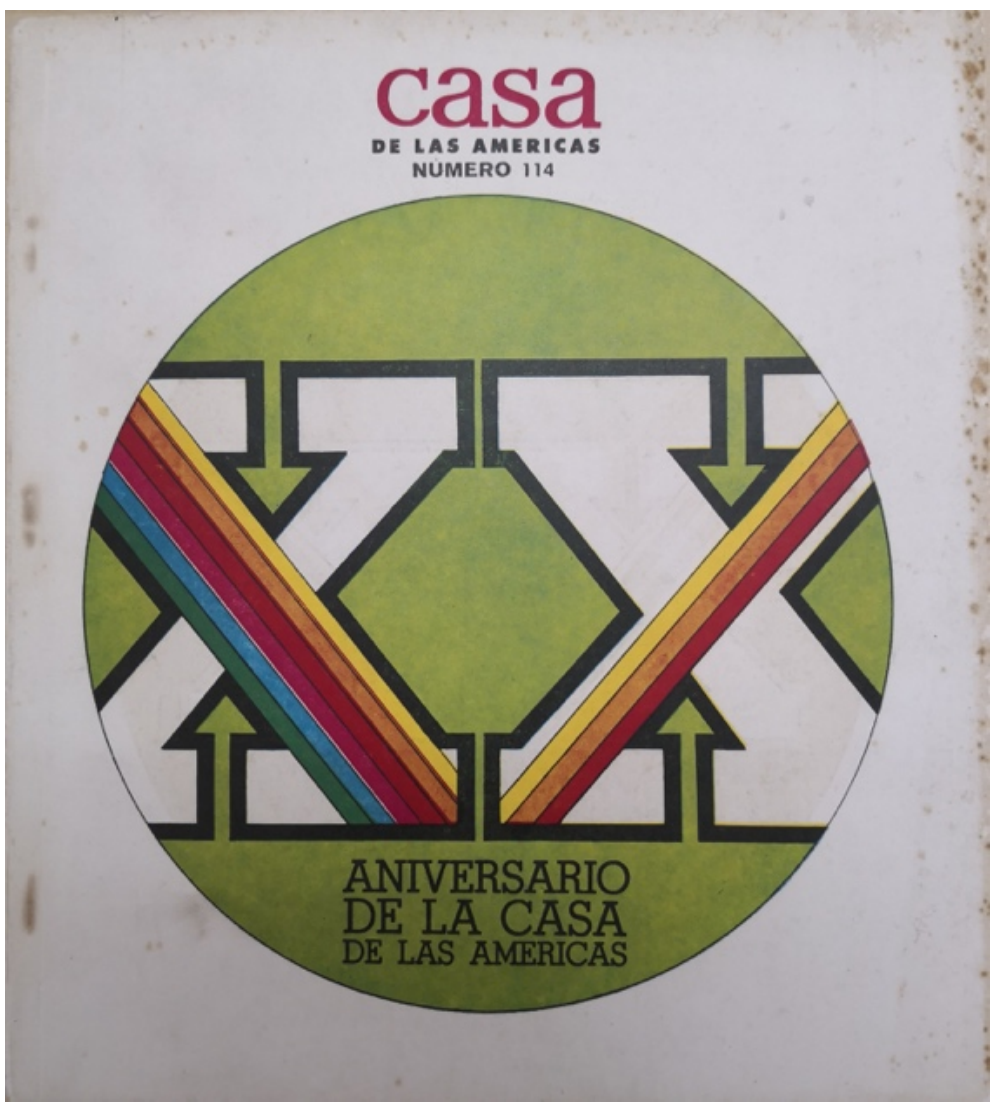

Portada de la revista Casa de las Américas, núm. 114, mayo-junio, Cuba, 1979.

Una Casa en la que se escuchaban palabras recurrentes: revolución, utopía, esperanza, transformación, América, emancipación, imperialismo y pueblo. Un hogar en el que confluyeron, no sin conflicto, la política y la junio, 1979, pp. 3-7. 
cultura. Interesa remarcar la idea de que esta revista, a pesar de ser un órgano del Estado cubano, es una fuente histórica para estudiar el disenso, la diferencia y el conflicto en un proceso histórico complejo, como el que se inició en Cuba desde los años cincuenta.

La revista comenzó con un tiraje de 2000 ejemplares, para 1962 esta cifra se duplicó; en 1965 subió a 9 000; durante la década de los setenta se incrementó a 12000 ejemplares y a 15000 en los años ochenta, época sobre la cual profundizan estas líneas. ${ }^{4}$ En la actualidad se puede consultar tecleando su nombre y picando un par de ventanas cibernéticas. ${ }^{5}$

\section{LAS REVISTAS COMO INDICIOS}

Este texto se construyó a partir de la clave metodológica para el análisis de revistas literarias y culturales, en la que cada número es entendido como un indicio, una huella que expresa universos de significados amplios y no unívocos. Como lo apuntó el historiador italiano Carlo Ginzburg, es cierto que todos los historiadores trabajan con indicios; sin embargo, para comprender lo que él llama "paradigma indiciario" es importante reconocer que el acercamiento documental puede hacerse desde estrategias y objetivos cognoscitivos diversos, reconociendo que "la producción de las fuentes en determinadas sociedades está ligada de manera directa a las relaciones de fuerza que existen al interior de esa misma sociedad determinada" ${ }^{6}$

Así, uno de los focos del paradigma indiciario estaría puesto en entender las relaciones de poder y dominación desde huellas tenues, particularidades, rasgos documentales casi imperceptibles y, sobre todo, poco atendidos en términos de interpretación histórica. Para el caso que ocupa estas líneas, importa señalar que Casa de las Américas, es un documento de fundamental valía para comprender las complejas relaciones entre política y cultura, justamente porque en sus páginas se reflejaron contradicciones y matices en torno al ideal y práctica de la Revolución cubana.

Sobre las dos primeras décadas de esta revista existen diversos trabajos de gran valía intelectual. Para Claudia Gilman, esta revista cubana fue una suerte de centro gravitatorio que contribuyó a la consolidación de la red

4 Nadia Lie, Transición y transacción. La revista cubana Casa de las Américas (1960-1976), p. 24.

5 Portal de la revista Casa de las Américas,

http://www.casa.co.cu/publicaciones/revistacasa/270/revista.html, consultado el 1 de marzo de 2019.

6 Carlo Ginzburg, “Intervención sobre el paradigma indiciario”, Tentativas, Argentina, Prohistoria Ediciones, 2004, p. 122. 
letrada latinoamericana en los años sesenta y setenta. ${ }^{7}$ El trabajo de Judith Weiss Casa de las Américas: An Intellectual Review in the Cuban Revolution $^{8}$ problematiza el tema de las redes intelectuales y su relación con la complejidad ideológica en la época, no sólo desde América Latina, sino un marco explicativo de alcance global. Por su parte, Idalia Morejón estudió diversas polémicas culturales y políticas que tuvieron como espacio de enunciación las revistas Casa de las Américas y Mundo Nuevo; ambas publicaciones expusieron formas divergentes de comprender el campo intelectual latinoamericano, la cultura, la relación estética-política entre otros temas. $^{9}$

Quienes han estudiado esta publicación coinciden en que la revista es presencia y enunciación, pero también borramiento, contradicción, silencio. Siguiendo con el paradigma indiciario como forma de acercamiento a las revistas, en este texto se colocará el foco de atención en tres números publicados durante la década de los años ochenta, época fundamental para comprender los procesos de transformación y continuidad en las relaciones entre política y cultura en la isla caribeña y que ha sido menos estudiada respecto a su época fundacional o de consolidación.

Estos documentos son testimonio de un tiempo histórico que puede caracterizarse como una bisagra entre un momento en el que se disputaron y construyeron diversos proyectos emancipatorios y una nueva época signada con la palabra "neoliberal", la cual es un concepto que, si bien puede definir a grandes rasgos un proceso global, necesita obligadamente una lectura más fina que problematice sus particularidades histórico-sociales.

Para Roberto Fernández Retamar es fundamental ver en el entramado de colectividades que hacen una revista, la cual es para él una especie de opereta aperta, un taller o laboratorio. "El carácter colectivo de la revista no se refiere sólo, ni primordialmente, al hecho de que en ella aparezcan materiales de varios autores. Se refiere sobre todo a que es la obra de un equipo, o de varios. Lo que no está reñido con el papel, por lo general importante, que en ella desempeña una persona”. ${ }^{10}$ De diversas colectividades artísticas e

7 Véase Claudia Gilman, “Casa de las Américas (1960-1971), un esplendor en dos tiempos” en Carlos Altamirano y otros, Historia de los intelectuales en América Latina I. Los avatares de la ciudad letrada, pp. 259-284.

8 Véase Judith Weiss, Casa de las Américas: An Intellectual Review in the Cuban Revolution, Estudios de Hispanofilia, Chapel Hill, 1977.

9 Véase Idalia Morejón Arnaiz, Política y polémica en América Latina. Las revistas Casa de las Américas y Mundo Nuevo, México, Ediciones de Educación y Cultura, 2010.

10 Roberto Fernández Retamar, "Casi un siglo de revistas culturales españolas e hispanoamericanas”, En la España de la eñe, Santiago de Cuba, Editorial Oriente, 2007, pp. 11-124. 
intelectuales, de sus distinciones y disensos, de sus interpretaciones y reinterpretaciones es indicio la revista.

En la década referida, además de Casa de las Américas, en Cuba se publicaron otras revistas importantes de diverso tipo como El Caimán Barbudo, Santiago, de la Universidad de Oriente, Signos, que hacía Samuel Feijoo, Letras Cubanas, Opciones, La Gaceta de Cuba y Unión, renovadas en 1987, Revolución y cultura, Bohemia. Cada uno de estos espacios revisteros es, sin duda alguna, un cúmulo inagotable de posibles interpretaciones indiciarias.

Para comprender por qué cada número de esta revista es un indicio y por qué los números elegidos son huellas de contradicciones entre posturas afines al proceso revolucionario, habría que señalar que en esa década seguían en pugna diferentes versiones de concepción y práctica del socialismo. Grosso modo se puede afirmar que una de las posturas dominantes es la que siguió los lineamientos soviéticos no sólo en materia de política económica, sino cultural y social; había otra postura no dominante como aparato de Estado, pero sí en términos de legitimidad cultural, que hacía eco de un socialismo de otra índole, de tradición martiana, guevarista, latinoamericanista, tercermundista. Ambas visiones son distinguibles en las páginas de Casa de las Américas.

La Cuba de entonces era dependiente del campo socialista en términos económicos, por lo tanto, además de enfrentar problemas internos de diverso carácter, cumplía un papel importante en relación con los conflictos geopolíticos de la época.

A partir de 1985 se evidenciaron errores cometidos en el sistema político y económico cubano derivados, en parte, de la estrecha relación con el régimen soviético. En ese año inició el llamado "Proceso de rectificación de errores y tendencias negativas”, el cual pretendió dar virajes profundos en materia económica, social y cultural. ${ }^{11}$

En 1985, había 2,5\% de funcionarios más que en 1971 (1\%). El fondo de esta burocratización se basa en un cambio de mentalidad: la creatividad y la capacidad de iniciativa de los seres humanos, lo más preciado que tiene Cuba, se verán frenadas, cuando ellas favorecen que cada uno se sienta realizado dentro de la sociedad. Esta burocratización, y lo que ella supone como rotura y atomización del pensamiento social, impidió toda reflexión sobre nuestros problemas y también sobre nuestro proyecto.

11 El "Proceso de rectificación de errores y tendencias negativas" da cuenta de una política de Estado en la que se modificó la política económica cubana en un contexto mundial delineado por un gran número de países socialistas que viraron hacia políticas económicas y modelos sociales capitalistas. Cuba, en cambio, apostó por la continuidad del socialismo. 
Ella provocó que el entusiasmo decayera y que se sustituyera por fórmulas rituales. Que la lengua se vaciara de contenido. Todo este proceso de deterioro prosiguió durante la segunda etapa. ${ }^{12}$

Como consecuencia del estancamiento económico vivido entre 1986 y 1989, de la caída del Bloque Soviético, de la disolución del Consejo de Ayuda Mutua Económica (CAME) y de cambios socioculturales, comenzó el llamado “Periodo Especial en tiempos de Paz". Dicho momento histórico es fundamental en la historia cubana, al ser un plan de resistencia civil en un momento de profunda crisis económica.

Casa de las Américas es un documento desde el cual se puede acercar a este denso y complejo momento de la historia del país. No sólo los discursos pueden ser tenidos por indicios, también su materialidad dice mucho sobre su tiempo. Mientras en sus textos está presente el debate, el sutil disenso, su materialidad refleja las dificultades para obtener materias primas para la impresión durante el Período Especial; en los discursos, pero también en las imágenes o en las notas finales impresas en letras pequeñas, se pueden rastrear los conflictos entre aquéllos que sostenían un discurso de unanimidad y homogeneidad ideológica y quienes defendían el derecho al disenso $\mathrm{y}$ al cambio al interior del proceso revolucionario.

\section{UNA CASA PARA ENCONTRARSE}

Como se dijo anteriormente, se utiliza la década de los ochenta como marco temporal sólo con fines metodológicos; en sentido estricto, una nueva etapa de esta revista fue distinguible a partir del triunfo de la revolución sandinista en 1979, proceso que replanteó el lugar de la utopía revolucionaria en el continente y le dio un giro al pensamiento intelectual latinoamericano.

Durante la década de los sesenta, la revista Casa de las Américas expresó la efervescencia y expectativa de la Revolución cubana. Fueron años en los que sus páginas dejaron huella de consensos más amplios y redes de artistas, intelectuales y escritores más diversas en términos de su politicidad. ${ }^{13}$

Sin embargo, en los años setenta cambió de forma importante la red de colaboradores de la revista, ello en el marco de los deslindes y fracturas intelectuales tras el Caso Padilla y en medio de lo que se ha llamado Quin-

12 Entrevista a Fernando Martínez Heredia, “Cuba, cincuenta años de revolución, nuestra edición especial”, http://www.humanite-en-espanol.com/spip.php?article165, consultado el 1 de marzo de 2010.

13 Graciela Pogolotti, Polémicas culturales de los sesenta, La Habana, Letras Cubanas, 2006. 
quenio Gris, ${ }^{14}$ el cual se puede definir como una época, por cierto, un tanto más amplia que un lustro, en la que se parametrizó la cultura evidenciando la censura y, a decir de los propios escritores y pensadores, también la autocensura. ${ }^{15}$

Tras el triunfo sandinista, el futuro continental parecía ser distinto. Un cambio de temporalidad es percibido en los números de la segunda mitad de 1979. El optimismo permeaba las páginas de la revista cubana a pesar de que su vigésimo aniversario coincidió con la muerte de Haydée Santamaría. Durante toda esta década será constante la rememoración y el homenaje a quien fuera su fundadora. Importa mencionar esto porque Santamaría es uno de los personajes de la historia cubana que vincularon la política y la cultura de formas distintas al canon de la época. Como huella basta mencionar que en la mayoría de los textos publicados como homenaje se le nombra no como Haydée Santamaría, sino como "Haydée", dándole un lugar al nombre propio, contraviniendo la costumbre del medio artístico e intelectual de reconocimiento a partir del apellido.

En el marco de cambios de época, en 1981 se convocó al Primer Encuentro de Intelectuales por la Soberanía de los Pueblos, celebrado en la ciudad de La Habana; sus memorias fueron recopiladas en el número 129 de la revista cubana. Este número constituye un punto de partida para indagar acerca del viraje en las reflexiones sobre la concepción de América Latina y la revolución continental, justamente porque el sandinismo amplió la geografía de la rebeldía triunfante. Los textos de este número son indicios para investigar acerca del disenso entre diversas concepciones y prácticas de socialismo y latinoamericanismo. En Casa de las Américas se publicaron textos cercanos a posturas dominantes alineadas con los parámetros culturales soviéticos, no sólo en materia de política económica, sino cultural y so-

14 El "Caso Padilla” marcó un momento de inflexión y ruptura en las constelaciones intelectuales que apoyaban el proceso revolucionario cubano. En 1968, las obras Fuera de Juego, de Heberto Padilla, y Los siete contra Tebas, de Antón Arrufat, fueron declarados por un jurado de escritores nacionales y extranjeros ganadores de los premios literarios que anualmente promovía la Unión de Escritores y Artistas de Cuba (UNEAC). Padilla ganó el premio en poesía y Arrufat el de teatro. Los libros fueron censurados, a pesar de haber sido impresos y distribuidos. Como indicio del conflicto se puede leer hoy, en las impresiones originales de las dos obras, un comunicado de la UNEAC que advierte sobre el contrario contenido ideológico de los escritos (véase Antón Arrufat, Los siete contra Tebas, La Habana, Ediciones Unión, 1968). Este hecho provocó una serie de deslindes y críticas a la parametrización y la censura por parte de intelectuales que durante la década de los ochenta participaron de la efervescencia cultural y política de esa década.

${ }^{15}$ Véase Ambrosio Fornet, "Casa de las Américas: entre la revolución y la utopía”, en Saúl Sosnowski (ed.), La cultura de un siglo. América latina en sus revistas, Buenos Aires, Alianza Editorial, 1999. 
cial, y también escritos cercanos a un socialismo entendido desde la matriz latinoamericanista. En el número 129 la voz dominante fue la de los segundos, aunque en el Ministerio de Cultura, al cual pertenecía Casa de las Américas, todavía dominaban posturas defensoras de la parametrización cultural y de la condena a las opiniones consideradas contrarrevolucionarias.

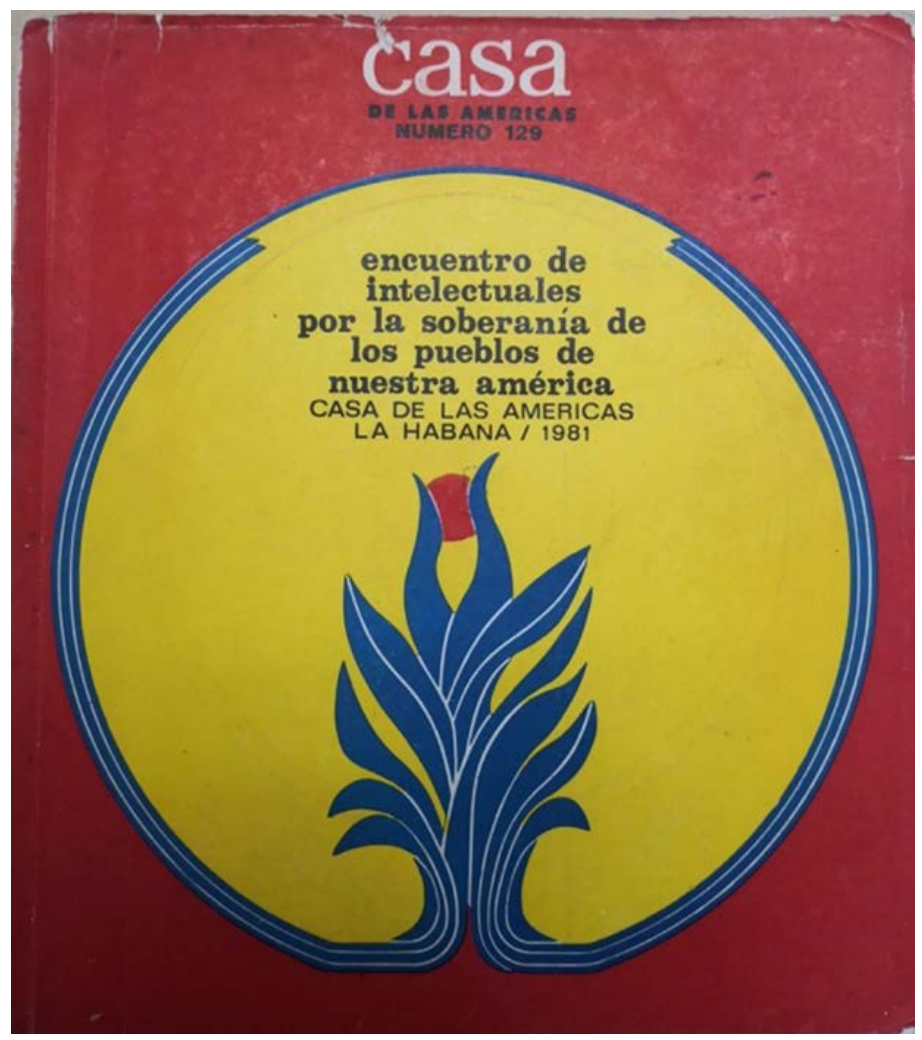

Portada de la revista Casa de las Américas, núm. 129, noviembre-diciembre, 1981.

En esa década de quiebre no sólo se implementaron nuevas formas de guerra, circulación del capital, configuración geopolítica, también se percibieron cambios en el lugar del pensamiento, la cultura y su relación con la política.

El discurso inaugural del ministro de cultura Armando Hart es interesante por varias razones. La primera de ellas obedece a la referencia sobre lo 
que el autor llamó nuestros intelectuales, definidos como aquéllos que defienden y levantan las banderas de una cultura popular y humanista genuina y creadora. Se entiende, por oposición, que el mensaje va dirigido también a los intelectuales que estaban fuera de ese "nosotros". Por otro lado, en este documento hay un explícito reconocimiento de posibles errores en el manejo de la política cultural:

Los revolucionarios no rehuimos el debate de cualquier tema, por escabroso que sea. Por supuesto no somos infalibles ni desconocemos que hayamos podido cometer errores en el desarrollo de la gestión cultural. Pero el problema consiste en que los enemigos, apoyándose en el control que ejercen sobre los medios de difusión cultural, están empleando una táctica encaminada a tratar de dividirnos y de entretenernos en discusiones de segundo orden, para evitar los análisis de primer orden. ${ }^{16}$

Sin embargo, a pesar de este reconocimiento, es claro que la atención estaba puesta en el imperialismo y la amenaza exterior y no en el debate en torno a los conflictos en materia de política cultural iniciados en 1968. En tanto, el mensaje que envió el escritor argentino Julio Cortázar decía que aquel evento debía ser una ventana para que los intelectuales miraran con ojos colectivos el horizonte de sus tierras y de sus destinos. Cortázar afirmó en aquel mensaje que había un enemigo más peligroso y repugnante que el imperialismo: "estoy hablando del enemigo interno, de las fuerzas reaccionarias que de manera abierta o embozada operan en el interior de cualquiera de los países latinoamericanos y caribeños sometidos al ataque abierto del imperialismo norteamericano". ${ }^{17}$

El texto de Ariel Dorfman también es indicio. En él concibe al gobierno de Pinochet como un laboratorio en el que se experimentaban fórmulas multinacionales que posteriormente se exportarían hacia otros pueblos. Era 1981 y Dorfman ya argumentaba, junto a otros, que no se trataba sólo de recetas que iban a apretar "el estómago, el sexo y el cerebro de los habitantes de nuestros países miserables y explotados”, sino había también una pretensión globalista, una tesis supuestamente válida para el mundo entero, que sería una cura milagrosa para el cáncer de la subversión. Se refería a las ideas que exponían, entre otros, Von Hayek, Friedman y Harbenger. ${ }^{18}$

16 Armando Hart, "Discurso de inauguración”, Casa de las Américas, núm. 129, noviembrediciembre, 1981, p. 11.

17 Julio Cortázar, “Mensaje”, ibíd., p. 19.

18 Se refiere al economista austriaco de principios del siglo XX, Friederich von Hayek, precursor de la teoría del neoliberalismo. 
El chileno ya estaba leyendo que Estados Unidos seguía firme con su política expansionista, pero también sostenía un nuevo interés por hacer que las fronteras se debilitaran económica y culturalmente. Escribió Dorfman: "no estamos exagerando"; ciertamente no era una exageración. "No hay que llamarse a equívocos". ${ }^{19}$ No sólo se estaba jugando la soberanía de los pueblos, sino su supervivencia. Por ello él veía como un factor de suma importancia que dentro de los propios Estados Unidos se estuviera generando un movimiento opositor a la administración de Ronald Reagan (1981-1989) que se estructuraba de forma paralela a la del gobierno de Magaret Thatcher. Este texto es un indicio importante para rastrear temporalmente el inicio de las explicaciones, elementos de análisis y críticas a una época histórica distinta, cuya importancia y complejidad apenas era atisbo en aquellos años.

Ante un contexto que el autor comparaba con el de los años previos al nazismo, a los pensadores y artistas no les quedarían otras armas que la inteligencia, la imaginación, la honradez crítica y el deseo de que dichas capacidades sirviesen para hacer eco en otros; para hacer del mundo un lugar comprensible y misterioso, hermoso y recto, en el que toca dudar y vivir. La resistencia implicaría formar pueblos intelectual y emocionalmente soberanos, en donde cada ser humano se convirtiera en un derecho humano. Decía entonces Dorfman:

no quieren invadir tan sólo nuestra geografía y nuestras pieles. También quieren penetrar y limpiar el último recinto de nuestras mentes, quisieran colgarnos en una pared, como un trofeo o una tarjeta postal. Quisieran que consumiéramos sus productos frívolos e innecesarios, que les exportáramos materias primas baratas, que hiciéramos los trabajos desagradables y sucios. Están dispuestos a saquear nuestros sueños junto con nuestros suelos. Propongo que nuestra obra literaria, que nuestra música, que nuestros colores salgan a la defensa de los pueblos. ${ }^{20}$

Tras hablar de los peligros nucleares, del imperialismo y del complejo escenario geopolítico, la declaración final de este encuentro de intelectuales proclamó su apuesta por la vida y la paz, en contra de la muerte. La palabra y la imagen tendrían que extremar la capacidad de persuasión, el poder de reclutamiento de las fuerzas creadoras y convencer a partir de la lucidez que es posible evitar el exterminio del ser humano. El poder de la inteligencia es invencible, decían entonces. ${ }^{21} \mathrm{~A}$ la luz de los años, estos textos quedan como

Ibíd., p. 25.

21 Varios autores, “Declaración final”, ibíd., pp. 34-36. 
indicio de una época en la que se vislumbraban cambios profundos, aunque su conceptualización, problematización y entendimiento aún está en proceso.

\section{INDICIOS DE UN CAMBIO GENERACIONAL. EL NÚMERO 180}

En el número 180 hay diversas huellas sobre un cambio generacional en lo que se refiere a la concepción del latinoamericanismo, de la revolución y la cultura. Para este momento los jóvenes que habían sido niños cuando el triunfo de la revolución comenzaron a participar en el campo cultural cubano en general y en particular de la revista Casa. Poco a poco, nombres como Leonardo Padura, Víctor Rodríguez Núñez, Senel Paz, Francisco López Sacha, Reinaldo Montero, Reina María Rodríguez, Miguel Mejides comenzaron a formar parte de un nuevo empeño literario y cultural. Todos estos escritores cubanos cursaron sus estudios universitarios siendo compañeros de escritores no cubanos que vivían en la isla. Este internacionalismo fue crucial para entender los virajes generacionales.

Según el crítico Rufo Caballero, ${ }^{22}$ la plástica cubana fue prodigiosa en la década de los ochenta. Diversos artículos de la época que reseñaron críticamente los nuevos impulsos de las artes plásticas son muestra de lo creativas que fueron diversas exposiciones en las que se problematizó el papel del espectador, se cuestionó la idea de autor, se construyeron nuevas espacialidades y se innovó estéticamente. ${ }^{23}$ Casa de las Américas fue una publicación cuyas páginas son ejemplo de la centralidad de la plástica cubana en esta época, de su importancia en la compleja relación que se tejió entre estética y política. Indicios de ello han quedado documentados en el número 180, cuya propuesta de diseño e ilustración estuvo a cargo del entonces joven artista César Beltrán, quien fue una de las muchas manos que hicieron posible esa "década prodigiosa” a la que se hizo referencia. César Ernesto, como firmaba en Casa de las Américas, estuvo a cargo de la propuesta de diseño de ese número en la que experimentó con la figura del payaso en términos plásticos.

En la portada aparece la imagen de un sujeto con el añadido caricaturesco de nariz y boca de payaso acongojado; en páginas interiores se juega con imágenes de payasos, mimos y arlequines. Una de las imágenes, la de la página 119, hubiese pasado inadvertida si no fuese porque la impresión de la revista salió mejor de lo pensado por su diseñador, director e impresores,

22 Rufo Caballero, “La década prodigiosa”, en El Caimán Barbudo, agosto, 1990.

23 Véase Margarita González y otros, Déjame que te cuente. Antología de la crítica en los ochenta, Consejo Nacional de las Artes Plásticas, Cuba, 2002. 
convirtiendo una broma interna en un problema de gran dimensión. Confiados en que la impresión de la revista no sería lo suficientemente buena como para que se notara de quién era el rostro del personaje con gorro de arlequín, el equipo encargado de editar la revista usó la fotografía truqueada del periodista cubano Luis Sexto, el cual, al reconocer su imagen en la revista Casa de las Américas hizo llegar sus reclamos a la dirección de la institución.

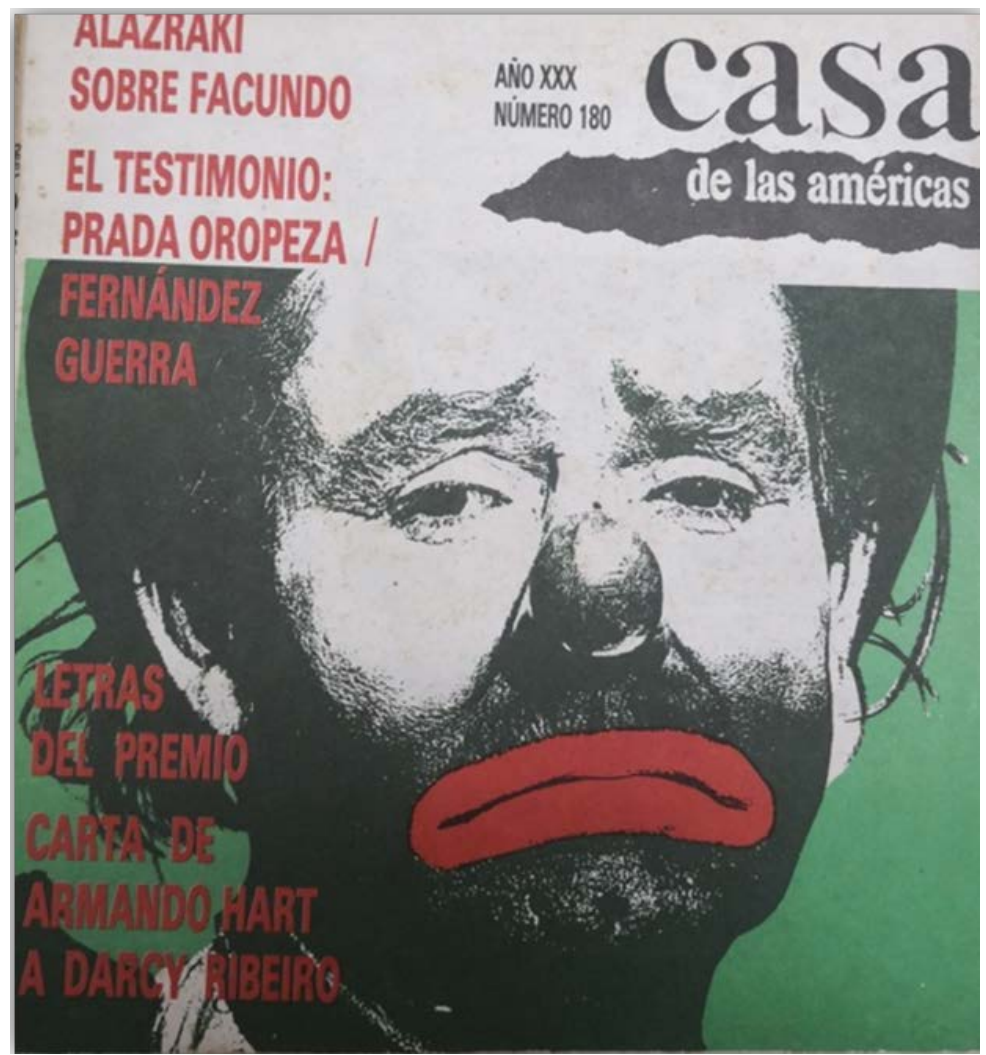

Portada de la revista Casa de las Américas, núm. 180, mayo-junio, 1990.

Al final de la sección “Al pie de la letra” del número 183, en un aviso para los lectores, se daban las siguientes razones para justificar el despido del director Arturo Arango, del redactor Roberto Urías y del diseñador César Beltrán. 


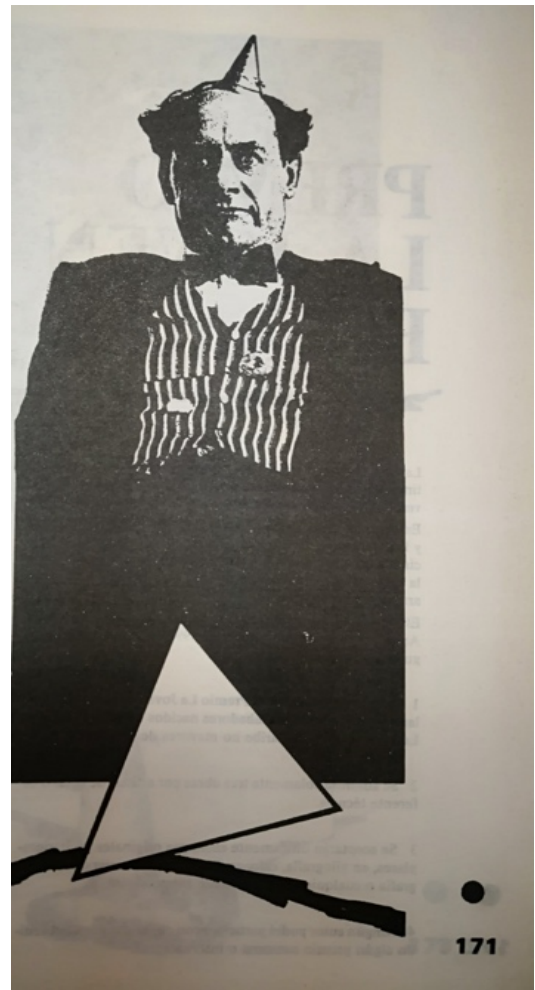

Ilustración, Casa de las Américas, núm. 180, mayo-junio, 1990, p. 171.

Quienes durante algún tiempo fueron director, redactor y diseñador de la revista ya no están con nosotros. La razón de esto último es que los tres incurrieron en una gravísima violación de la ética periodística, al valerse de las páginas del n.180 de Casa de las Américas para injuriar a un colega cubano, quien hizo la reclamación correspondiente. Al esclarecerse quienes eran responsables del hecho, no quedó otra alternativa que separarlos de esta publicación que es órgano de la institución. Como ello ocurrió en vísperas de mandar los materiales de este número a la imprenta, dejamos constancia de que casi la totalidad de dichos materiales fue compilada, editada y diagramada por el equipo saliente, lo que le ha sido reconocido en los aspectos materiales de su trabajo, y reiteramos en estas líneas en cuanto al aspecto intelectual del mismo. $^{24}$ 
Más allá de la anécdota habría que enmarcar el hecho en un contexto general en el que la broma expresaba la confrontación política entre visiones de la cultura diferentes.

En ese mismo número, el 180, el redactor Roberto Urías escribió una nota titulada "Un bromista colosal muere de luz y de orden", en el que se congratulaba de la publicación de un texto de Alberto Garrandés en $L a G a$ ceta de Cuba que estudiaba la relación entre lo histórico y lo político en la obra de Virgilio Piñeira Una broma colosal. Como se sabe, este último autor fue censurado durante los llamados años grises de la cultura cubana. En su texto Urías dijo "Si de algo estamos necesitados es de un diálogo permanente, enfático, que nos permita demostrar que soñamos con establecer un estado de cosas en el que cada cual tenga el derecho y el deber elemental de prescindir de la doble moral que, día a día, tiene diferentes manifestaciones castrantes". ${ }^{25}$

Respecto a la idea de América Latina, los números de esos años muestran dos cambios importantes: el primero fue la literaturización de la revista, es decir, un proceso en el que se fue privilegiando la publicación de textos latinoamericanos de corte literario. El segundo fue que se dio mayor cabida al pensamiento social de América Latina. Entre estos textos publicados no es vano señalar que se dio voz a algunos pensadores que explicitaron su preocupación sobre el estancamiento de la revolución, sobre la crisis política de la izquierda latinoamericana y la necesidad de reformular permanentemente los postulados y prácticas de los defensores del pensamiento crítico emancipatorio. Como ejemplo paradigmático habría que resaltar aquí la respuesta que en ese número publicó Armando Hart a una entrevista a Darcy Ribeiro, titulada "No tener miedo a pensar", publicada cinco números antes. En ella, Hart Dávalos se planteaba un diálogo crítico con el pensador brasileño, en el que recuperó una serie de acuerdos, no sin mencionar ciertos disensos teóricos y políticos. Indudablemente eran tiempos en los que fue patente cierta apertura y disposición a la crítica y autocrítica.

\section{INDICIOS DE LA CRISIS. EL NÚMERO 184}

El marco temporal de este texto se cierra en 1991, cuando cayó el Muro de Berlín, se disolvió el bloque soviético, los sandinistas fueron derrotados en las urnas y comenzó el Período Especial, con el recrudecimiento del bloqueo económico de Estados Unidos sobre el pueblo de Cuba. 
En 1991 inició una profunda crisis económica en la isla a raíz del colapso de la Unión Soviética y del COMECOM (Consejo de Ayuda Mutua Económica), el cual fue una organización de cooperación económica formada por países del bloque socialista y que buscó oponerse a los planes geoeconómicos de las organizaciones capitalistas. En 1992 Estados Unidos legalizó el embargo comercial, económico y financiero en contra de Cuba, lo cual recrudeció la crisis económica en la isla caribeña.

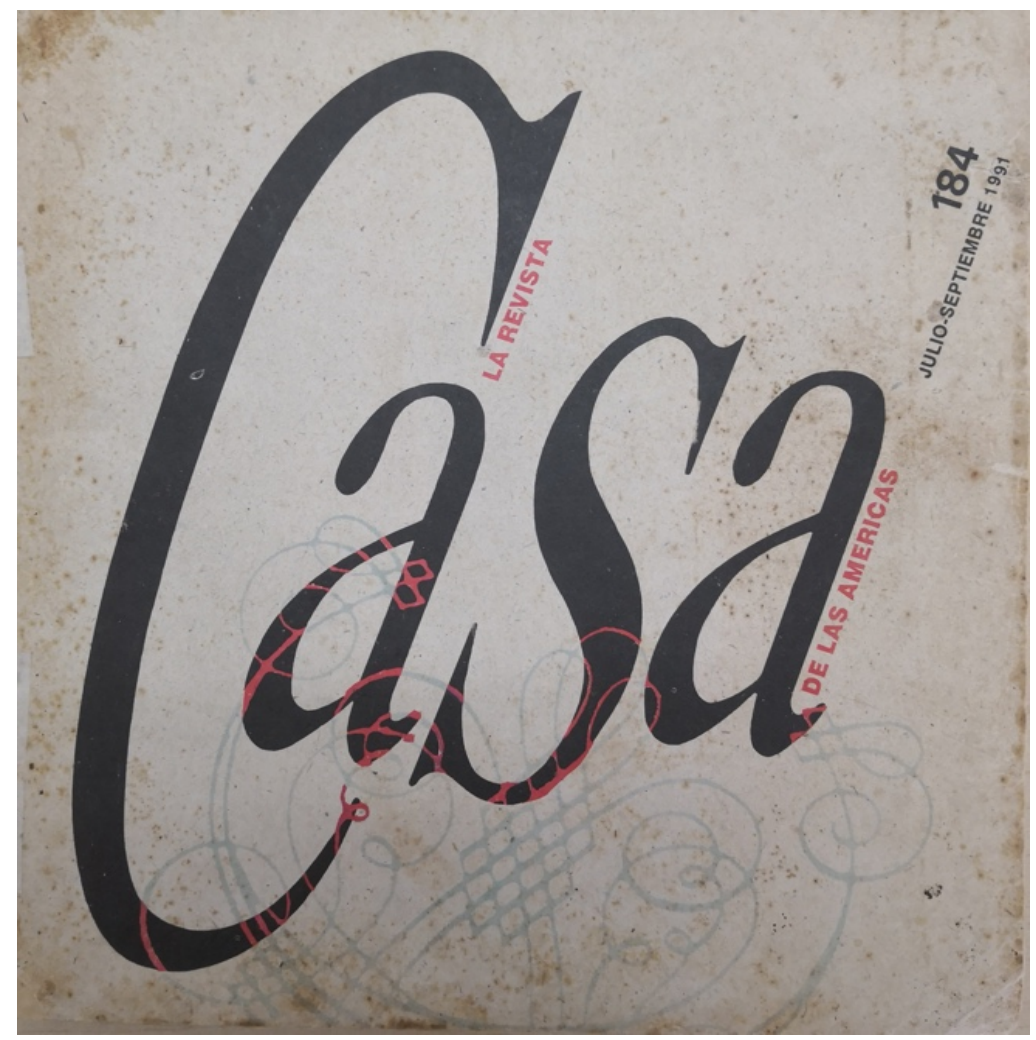

Portada de la revista Casa de las Américas, núm. 184, julio-septiembre, 1991.

La materialidad de Casa de las Américas es muestra de ello. En el número 184 se evidenció la carencia de insumos necesarios para su publicación, muchos de los cuales provenían de los países del Este. El número 184 materializó el llamado Período Especial en tiempos de Paz, el cual fue una propuesta de salida o estrategia de resistencia del gobierno cubano a la profunda crisis que azotó a la isla caribeña. 
Los artistas, intelectuales y pensadores cubanos supieron ver que venían tiempos de cambio y que era apremiante pensar, crear, debatir. A partir de la segunda mitad de los ochenta comenzaron a realizarse estudios que dieron cuenta de la existencia del mito de la unanimidad y homogeneidad, y voces se sumaron para que éste no fuese una forma dominante de explicación sobre lo cubano o lo latinoamericano.

El número 184 mostraba precariedad económica, pero no cultural. Sus páginas serán atisbo de una época de crisis material, pero también de creatividad y resistencia. El número inicia con una declaración de la revista en torno a los múltiples eventos que rememoraban el quinto centenario de la conquista de América. En él se decía:

La llegada del Quinto Centenario no puede ser ocasión para azuzar divisiones, rencores, altanerías y odios estériles, sino para insistir, con total respeto para las diferencias que son riquezas, en la integración, tan difícil como imprescindible de nuestra América. ${ }^{26}$

En otro de los textos del ejemplar, se publicó una serie de trascripciones de apuntes de lectura de Ernesto Che Guevara. La Historia verdadera de la conquista de la Nueva España aparece junto a La crónica del Perú seguida de La Araucana; están también esbozos de interpretación sobre Martín Fierro, Facundo o Trayectoria de Goethe. En otro texto del número 184, Roberto Fernández Retamar escribió sobre Rafael Alberti, lo que mostraba una animosa apertura cultural de la revista en la última década del siglo Xx. Raúl Hernández Novás, Jorge Amado y Cintio Vitier son autores de ese número. Una de las reseñas publicadas en las páginas finales es un largo homenaje a Jorge Luis Borges, autor que durante muchos años no fue pronunciado en Cuba con la fuerza que merecería, dada su indiscutible importancia en la configuración literaria de América Latina. ${ }^{27}$

Es menester resaltar la idea de que a la revista hay que acercarse atendiendo no sólo las huellas evidentes que dejan los discursos, sino aprender a interpretar las tenues, casi invisibles, aquellas delineadas por una nota al pie que pasa desapercibida, por un error de impresión o por el cambio de diseño de portada o interiores. Justamente fue en una nota impresa con letras pequeñas al final de la revista que se anunció el retorno de Umberto Peña, Américas, núm. 184, julio-septiembre, 1991, p. 13.

27 Andrés Zavala, “Borges a contraluz”, ibíd., pp. 150-156. 
quien había sido diseñador de la revista durante la década de los sesenta, la más icónica de la revista. ${ }^{28}$

\section{LA APUESTA INDICIARIA}

Los acervos de revistas literarias y culturales de América Latina son indudablemente un vasto caudal de indicios para pensarnos no sólo desde la palabra hecha discurso, sino también a partir de aquella que es silencio, disputa, de la que fue acallada o contradictoria. Aprender a mirar los indicios del pasado que palpitan en nuestra contemporaneidad contribuirá a la comprensión de nuestro tiempo, de lo contrario, difícilmente apuntaremos a un porvenir cuyos proyectos se sustenten en el reconocimiento de los densos y complejos tiempos que nos conforman.

La apuesta de estas líneas fue sumarse a la discusión sobre el estudio de las revistas literarias y culturales, hacerlo desde la propuesta metodológica que concibe a cada número como unidad material, simbólica y discursiva desde la que se pueden comprender dimensiones amplias de la vida social. Retomar a la revista como indicio es otra clave metodológica para el estudio de una de las fuentes privilegiadas para la comprensión de la historia cultural del siglo XX.

Otra de las apuestas fue también problematizar algunos aspectos de la historia cultural de Cuba durante la década de los ochenta. Esa época conforma un tiempo histórico abierto a la reflexión futura; las generaciones venideras plantearán una serie de interrogantes sobre estos años que sin duda son determinantes en la comprensión de nuestro presente y porvenir.

Nuestra contemporaneidad requiere acercamientos diversos y no unívocos sobre nuestro pasado reciente. Una de las posibles formas de hacerlo es buscar en los detalles mínimos, en las ausencias, en lo silenciado o silencioso, en lo no dominante, pistas para comprender nuestras formas de estar y significar el mundo. La Cuba de los años ochenta es indicio de cómo se fueron transformando las certezas construidas décadas antes; por la centralidad que tuvo en la historia del continente, el acervo documental de Casa de las Américas de estos años es una fuente imprescindible para la comprensión de la historia de la cultura más allá de las fronteras insulares.

28 Roberto Fernández Retamar, “Un trabajador llamado Peña”, Casa de las Américas, núm. 171. 


\section{BIBLIOGRAFÍA}

Altamirano, Carlos (dir.), Historia de los intelectuales en América Latina, volumen II. Los avatares de la ciudad letrada, España, Katz, 2008.

Arrufat, Antón, Los siete contra Tebas, La Habana, Ediciones Unión, 1968.

Benedetti, Mario, “El Premio número veinte”, Casa de las Américas, núm. 114, mayo-junio 1979, pp. 3-7.

Caballero, Rufo, “La década prodigiosa”, El Caimán Barbudo, agosto, 1990.

Consejo de Redacción, “La Casa de las Américas ante el Quinto Centenario”, Casa de las Américas, núm. 184, julio-septiembre, 1991, pp. 13-13.

Cortázar, Julio, “Mensaje”, Casa de las Américas, núm. 129, noviembre-diciembre, 1981, pp. 18-19.

Dorfman, Ariel, “Mensaje”, Casa de las Américas, núm. 129, noviembre-diciembre, 1981, pp.23-25.

Entrevista a Fernando Martínez Heredia. "Cuba, cincuenta años de revolución, nuestra edición especial”, http: //www.humanite-enespanol.com/spip.php?article165, consultado el 1 de marzo de 2010.

Fernández Retamar, Roberto, "El más grande honor de mi vida”, www.lacult.unesco.org/docc/Dossier_50_Aniv_CASA_09.doc, consultado el 25 de febrero de 2019.

Fernández Retamar, Roberto, “Un trabajador llamado Peña”, Casa de las Américas, núm. 171, noviembre-diciembre, 1988.

Fernández Retamar, Roberto, En la España de la eñe, Santiago de Cuba, Editorial Oriente, 2007.

Fornet Jorge, y otros, Casa de las Américas, Fundación de Sevilla, http://www.casa.co.cu/pdfmemo/1959-1969.pdf

Gilman, Claudia, “Casa de las Américas (1960-1971), un esplendor en dos tiempos”, en Historia de los intelectuales en América Latina I. Los avatares de la ciudad letrada, Carlos Altamirano (dir.), España, Katz, 2008, pp. 259-284.

Ginzburg, Carlo, “Intervención sobre el paradigma indiciario”, Tentativas, Argentina, Prohistoria Ediciones, 2004, p. 122.

González, Margarita y otros, Déjame que te cuente. Antología de la crítica en los ochenta, Consejo Nacional de las Artes Plásticas, Cuba, 2002.

Hart, Armando, “Discurso de inauguración”, Casa de las Américas, núm. 129, noviembre-diciembre, 1981, pp. 7-17.

Lie, Nadia, Transición y transacción. La revista cubana Casa de las Américas (19601976), Bélgica, Ediciones Hispamérica, 1996.

Morejón Arnaiz, Idalia, Política y polémica en América Latina. Las revistas Casa de las Américas y Nuevo Mundo, México, Ediciones de Educación y Cultura, 2010.

Pogolotti, Graciela, Polémicas culturales de los sesenta, La Habana, Letras Cubanas, 2006. 
Sosnowski, Saúl (ed.), La cultura de un siglo. América latina en sus revistas, Buenos Aires, Alianza Editorial, 1999.

Urías, Roberto, “Un bromista colosal muere de luz y de orden”, Casa de las Américas, núm. 180, mayo-junio, 1990.

Weiss, Judith, Casa de las Américas: An Intellectual Review in the Cuban Revolution, Chapel Hill, Estudios de Hispanofilia, 1977.

Zavala Andrés, “Borges a contraluz”, Casa de las Américas, núm. 184, julioseptiembre, 1991, pp. 150-156. 